\title{
Sustainability of the College of Arts and Sciences Community Extension Programs in Brgy. Masalipit, Bulacan: Basis for Proposed Enhancement Program
}

\author{
Gary A. Garay, Celia Ligaya A. Verano, Irene B. Magistrado \\ Faculty Members, College of Arts \& Sciences Arellano University, Legarda, Manila, Philippines \\ Email: gary.gray1011@yahoo.com
}

How to cite this paper: Garay, G. A., Verano, C. L. A., \& Magistrado, I. B. (2021). Sustainability of the College of Arts and Sciences Community Extension Programs in Brgy. Masalipit, Bulacan: Basis for Proposed Enhancement Program. Journal of Human Resource and Sustainability Studies, 9, 106-121.

https://doi.org/10.4236/jhrss.2021.91008

Received: May 1, 2020

Accepted: March 13, 2021

Published: March 16, 2021

Copyright $\odot 2021$ by author(s) and Scientific Research Publishing Inc. This work is licensed under the Creative Commons Attribution International License (CC BY 4.0).

http://creativecommons.org/licenses/by/4.0/

\begin{abstract}
Community extension is an important program that is organized by schools in order to help in the development of communities within the areas where the school or any specific learning institution is inhabited. The Arellano University Community Extension \& Development Office serves as the outreach and extension arm of the university. Its main objective is to ensure in its adopted community that livelihood programs are existent, flourishing and can very well support families who are not well-off. Because of this, the College of Arts and Sciences (CAS) has chosen Barangay Masalipit in Bulacan. This research aims to determine the sustainability of CAS programs so that the people living in this community may be helped in living a decent and dignified life, a life that can someday be given a chance to progress and develop so that they too may be able to help more. It has been found out that most of the CAS programs can be sustainable such as Literacy, Wellness, Environmental, Behavioral programs. This means that the following are sustainable. However, the Legal Awareness and History Society are found to be in a lower rank which means that the program can still be improved or retrofitted.
\end{abstract}

\section{Keywords}

Community Extension Programs, History Society, Literacy Program, Sustainability

\section{Introduction}

Community extension is an important program that is organized by schools in order to help in the development of communities within the areas where the 
school or any specific learning institution is inhabited. Since schools cater to the learning of students, the best service that it could also give to the children in its neighboring communities is to supplement them in their learning, study needs and in other areas of activity where living and survival can be viable.

\section{Ease of Use}

As per mandate of the Commission on Higher Education (CHED), the school's tri-focal function which includes development of Research Extension services, Method of Instruction, and Community Extension Services are three important areas that the school must focus on to become a totally functioning institution of the country and also to adhere in the government's campaign of holistic development by its people.

However, much still has to be done in order to completely outdo such task. The cooperation of the people from the community, the trust of parents to community officials such as daycare and social workers, including volunteers and other important groups and organizations that must be completed are some of the much-needed works to be addressed upon.

\subsection{Selecting a Template}

Though it can never be denied of the benefit it costs, still a lot of things are needed in order to make an easy access to free education, medicines, and other important government services that people need, mostly those who are in far-flung areas and in those which do not even have electricity nor the internet to sustain their daily lives.

The Arellano University Community Extension \& Development Office serves as the outreach and extension arm of the university that has vigorously sustained the process of social change and transformation towards self-efficiency and self-reliance towards nation building over the years (http://www.au.comdevoffice.ph/).

With its mission statement of "Providing appropriate and relevant community outreach program and services that would empower partner communities to the process of development of their communities until they reach self-sufficiency and self-reliance", Arellano University aims to see a community filled with people who have utmost enthusiasm for growth and development. People who are not afraid to explore the world out of their comfort zones, and people who are competitive in doing their jobs yet compassionate and grateful for all the things that have happened.

The College of Arts \& Sciences, in cooperation with its faculty members, have come up with community extension programs that the college has adopted when it first went to Brgy. Masalipit, and when it became the official adopted community of Arellano University. Since then, so much have happened and a lot of things took place which are all for the benefit of the community. Since the college caters to different programs and therefore also caters to different areas of development, it has been agreed upon that each department shall come up with 
each project that can be developed to be adopted totally by the Barangay. The Languages Department has its literacy program which caters to the education of the youth in the Barangay most specifically those who are officially enrolled in the Day Care Center. Every visit, the Language Department, together with its faculty and students would spend time with the children in reading, playing, counting numbers and in some writing and storytelling sessions. The best accomplishment that concerns the department, however, was the regular promotion of the students it had sponsored in the next year level of learning as they get promoted in their preparatory and elementary years.

\subsection{Maintaining the Integrity of the Specifications}

The Physical Education department has developed a wellness program that covers mothers, middle-aged and young individuals in the community. This program is regularly given to the people of Brgy. Masalipit during visits sponsored by the PE Department with a theme of developing a sound and healthy body, thereby inculcating in the people the importance of movement and exercise in our day-to-day lives. The PE teachers hold Zumba and aerobic classes ranging from 45 minutes to an hour at the covered court with participating villagers in the town. As of the moment, the program continues and the members are growing in number as they slowly realize how much valuable is it in their lives.

The Psychology department, as they regularly visit the place, carries with them the Personality Development and Counselling Program to people in the community who needs a personality overhaul especially in the aspect of behavior and much so, in the physical and intellectual development. They give advice to people on how to make their lives better by making themselves contended with what they have and rationalizing to discover the importance and use of each current situation.

The Science and Mathematics department advocates the Environmental Awareness program which promotes love for the environment and awareness of the implications of several environmental catastrophes that took place in our country such as forest denudation, increased flooding, and proliferation of highly-urbanized than rural and environmentally-friendly areas, not to mention, climate change and its drastic effects. They usually invite speakers who give short talks on certain environmental programs that may be adopted in the community such as hydrophonics (a form of gardening with no soil) (D' Anna, 2020), and other outdoor activities that encourage sustainable living.

The Social Science department has established years ago in the place a History Club that deals with the study of unknown trivial facts about certain figures in the history of the country, in the world, and the important personalities and events that come along with it, these encourage the children in the Barangay to study harder and gain interest in the subject-matter. It has also developed in the children patriotism and love for country as they become aware of our heroes' 
contribution in attaining freedom and in fighting tyranny and oppression. As proof of their interest, some of these children get to be included in quiz bees and contests and get to represent their schools either in the provincial or regional level competitions.

The Political Science department established the Legal Awareness program which is open to all citizens in Brgy. Masalipit. During their visit, they conduct free legal advices from our students. There is a strict reminder, however, that since the participating students are not yet experts in law, what can be given to them are only random advices which are verifiable before a present legal expert. This they do in order to raise a point of awareness on certain rights that people can do in case someone raises arm against them, this move can prompt them to make a research and know their rights as people of the country. Because of this program, some of the children get encouraged and manage to somehow seek for a scholarship to be able to take such program.

\section{Prepare Your Paper before Styling}

Figure 1 shows the conceptual framework of the study. It illustrates the different phases or stages in attaining sustainability. Planning is an important aspect of the project, the people involved in this activity should be able to provide fruitful insights on how to make such program work. An important aspect of in the planning stage is the consolidation of the different opinions coming from involved individuals. As the old cliché says "two heads are better than one" so it is better to set aside differences and misunderstandings so that a more substantial outcome can materialize. Proper resources are always important in making things possible. All our objectives can easily be achieved if there is an appropriate use of facilities, this makes things easier to do. Two hands are always better than one, this means that certain tasks must be designated to proper individuals who can deliver the job competently, efficiently and with passion. If this can be accomplished, everything else will run smoothly. Putting things all together is like mixing up several ingredients to complete a recipe, condiments and spices

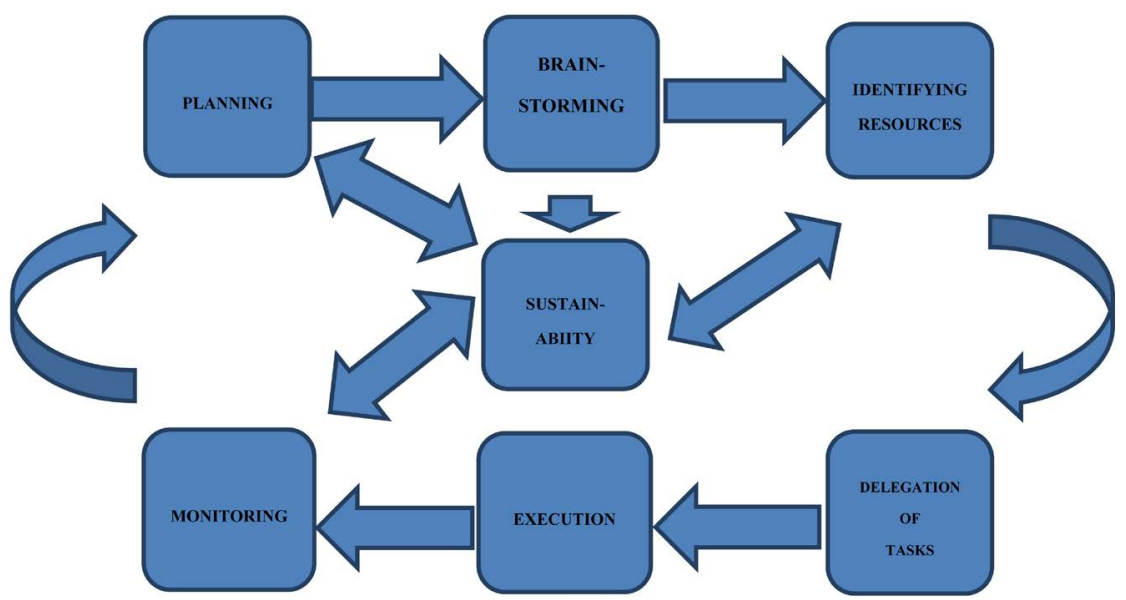

Figure 1. Conceptual framework. 
are necessary in order to make the food tasty. Same as well when doing something, if all tasks are accomplished well as the workers put their hearts and attention, the product will come out naturally splendid. Maintaining an effective and useful process should not stop in its full application and implementation, it definitely requires monitoring so that so that changes, challenges and problems along the way may either be anticipated or resolved with the most fitting solution. All of these stages make an ideal and sustainable project or activity that will surely benefit more stakeholders. Putting it all together makes sustainability of any program possible, hence, with emphasis on proper planning and continuous monitoring, any program will not just be successful but most of all, will last for as long as it is useful to the people.

\subsection{Abbreviations and Acronyms}

In view of the foregoing study, the following problem statements are intended to be resolved namely:

1) What is the demographic profile of the respondents in terms of:

a) Age;

b) Gender; and

c) Socio-economic status?

2) How beneficial useful are the CAS Community Extension Programs in terms of raising awareness in areas such as:

a) Literacy;

b) Wellness of the Body;

c) Wellness of the Mind;

d) Environmental;

e) Historical; and

f) Legal aspects of a person?

3) What possible recommendations can be given to develop or further enhance the said projects?

PURPOSE OF THE STUDY:

This study is deemed beneficial to the following stakeholders:

CAS Faculty-this assessment can serve as basis for future enhancement or redirection of the said program if in case there are changes that are needed to be met.

Brgy. Masalipit Residents - this study can further decide if the program can be taken to its next level which is more suitable to the growing needs of its stakeholders, then, it can be maintained because many others are still in need of it.

Future Researchers-basis for further research and development can be determined through this study.

\subsection{Units}

\section{METHODOLOGY}

This chapter presents the type of research that was conducted, the respon- 
dents considered and, the sampling technique to be used, including the data gathering procedure that must be done and the important statistical methods that were employed in analyzing and interpreting those gathered data.

The research is descriptive in nature because it describes and characterizes the population in a phenomenon being studied upon. However, it does not even answer the questions how, when or why these characteristics were acquired or have occurred.

Purposive sampling was also used in the study since it is a non-probability type of sampling that is based on the characteristics of a population and in the objectives of the study (Dudovskiy, 2020).

There were three hundred fifty-one respondents considered since in our current census, the total population in the community is two thousand eight hundred and eighty, respectively. The respondents considered for the study were selected citizens in the said Barangay who, at the same time, also have children housed in Barangay Masalipit's Day Care Center. Included also in the list of qualified respondents are those who are enjoying and are participating in the different programs of the College.

\subsection{Equations}

The Slovin's formula, a formula which determines the number of respondents needed (http://www.statisticshowto.com/), revealed such number of respondents. Slovin's formula allows researcher to determine the sample size that will ensure reasonable accuracy of the results.

$$
n=\frac{N}{1+N e^{2}}
$$

where $n$-the number of samples;

$N$-total population;

$\mathrm{e}$-margin of error.

For example, with a total population of 2880 and a confidence level of 95 percent (giving you an alpha level of 0.05), the result that will be obtained using the given solution will be:

$$
\begin{gathered}
n=\frac{2880}{1+2880 \times 0.05^{2}} \\
n=\frac{2880}{1+2880 \times 0.0025} \\
n=\frac{2880}{1+7.2} \\
n=\frac{2880}{8.2} \\
n=351.2 \sim 351
\end{gathered}
$$

A self-made questionnaire which has been translated in layman's term (Taga$\log$ ) was made as it was verified by an expert both in content and in language. 
The questionnaire is made up of two parts. Part 1 highlights the profile of each of the respondents which includes age, gender, and socio-economic status. Part 2 is made up of variables that could measure how beneficial are the Community Extension Programs of CAS, and the corresponding variables that lie along with it. In order to exactly quantify the results of the data gathered, the researcher adopted the standard equivalence and verbal description for each data gathered.

These are as follows:

Likert Scale:

4.51 - 5.00-5-Very Highly Beneficial (Lubhangnakatulongng Malaki)

3.51 - 4.50-4-Highly Beneficial (Nakatulongng Malaki)

2.51 - 3.50-3-Beneficial (Nakatulong)

1.51 - 2.50-2-Less Beneficial (Hindi gaanongnakatulong)

1.0 - 1.50-1-Not Beneficial ( Walangnaitulong)

The sample questionnaire is hereby attached for further reference and verification which can be found at the end of the manuscript.

\section{QUESTIONNAIRE}

Dear Respondent:

It is with deep gratitude that we, the researchers in the study entitled: Sustainability of College of Arts \& Sciences Community Extension Programs in Barangay Masalipit, Bulacan: Basis for Proposed Enhancement Program sought your cooperation in this endeavor. Kindly fill-out the necessary details for the first part of the questionnaire, and indicate your appropriate responses for the variables or statements given in the second part:

Part 1: Respondents' Profile:

Name:

Gender:

Age:

\section{Socioeconomic Status:}

\section{Part 2:}

Directions: Kindly put a check on your intended responses for the following conditions. Your responses will have corresponding verbal and numerical interpretations namely:

4.51 - 5.00-5-Very Highly Beneficial (Lubhangnakatulongng Malaki)

3.51 - 4.50-4-Highly Beneficial (Nakatulongng Malaki)

2.51 - 3.50-3-Beneficial (Nakatulong)

1.51 - 2.50-2-Less Beneficial (Hindi gaanongnakatulong)

1.0 - 1.50-1-Not Beneficial (Walangnaitulong)

\section{List Of Variables}

$\begin{array}{lllll}5 & 4 & 3 & 2 & 1\end{array}$

\section{Literacy Program:}

1. Can count numbers from 1- 20.

2. Can read short words and sentences.

3. Can read and understand short statements.

4. Can follow simple or short instruction with minimal assistance.

5. Can write their respective names and other short-word descriptions. 


\section{Continued}

Environmental Awareness Program:

1. Can understand the importance of taking care of our environment.

2. Have realized the bad effects of improper care of our surroundings.

3. Recognizes the importance of taking care of our plants, animals trees and other environmental living beings.

4. Recognizes the importance of biodiversity and ecosystem.

5. Promotes quality of life by engaging in noteworthy environmental activities such as tree-planting and reforestation.

\section{Wellness Program:}

1. Understands the importance of preserving good health.

2. Recognizes the benefits brought about by exercise and doing certain activities to one's body.

3. Gives importance to right amount of food intake and diet as contributory factors for having good health.

4. Recognizes the importance of having clean surroundings as contributing factors for having good health.

5. Recognizes the importance of a pollution-free ambience in achieving a healthy life.

\section{Mental Health Awareness Program:}

1. Encourages positive well-being and coming up with happy thoughts.

2. Recognizes the importance of having someone to talk to in the midst of important situations.

3. Recognizes the importance of emotional stability in combating certain issues such as bullying, stalking or discrimination.

4. Acknowledges the presence of loved ones, family, relatives and friends as important sources of strength and inspiration.

5. Recognizes the presence of loved ones, family, relatives and friends who can be of utmost help when problems set in.

\section{Legal Awareness Program:}

1. Have realized basic rights and privileges as Filipino citizens living in their own country.

2. Recognizes basic legal terminologies such as arrest and search warrants and its legal implications.

3. Awareness of certain legal considerations in the performance of duties, tasks and obligations.

4. Awareness of certain legal considerations in dealing with different people, organizations and some other entities.

5. Awareness of the legal considerations and responsibilities upon entering certain agreements.

\section{Historical Society:}

1. Valuing of certain historical accounts such as memorable artifacts and mementos are developed in concerned people.

2. Historical places are recognized as important in preserving rich culture and tradition.

3. Recognizing historical situations as important in putting substance to our identities as Filipinos.

4. Recognizing the important contributions of our heroes in the pursuit of freedom.

5. Developing nationalism and love for one's country.

For the interpretation of results, a score of almost 5 or less than 5 means that the program has been very highly beneficial and highly beneficial. This means that these programs were highly sustainable and can still continue in the coming 
days. A verbal interpretation of very highly sustainable or highly sustainable means that the work is noteworthy to be maintained as part of the school's department's programs. Programs which obtained an overall weighted mean (OWM) of 4 or less than 4 means that these have been beneficial and would therefore need enhancement as it continues in the future. Those projects which had less beneficial remarks must either be re-organized, retrofitted or improved in order that it could be a more useful program for the community.

For the demographic profile of the respondents, the researcher came up with an ideal age bracket as per suggested by an expert, these are the following: 18 23, 24 - 31, 32 - 39, 40 - 47, 48 - 54 and 56 - 60, and 61 years old and above, respectively. For the socio-economic status, the researcher heavily considered different financial situations including the rural and urban differences in terms of salary and price of commodities. The list is as follows:

Upper Class-(1 Million-5 Million net worth with a liability of not more than 5 Million);

Middle Class-(1 Million-2.5 Million net worth with a liability of not more than 2 Million);

Lower Class-(900,000.00-1.5 Million net worth with a liability of more than 2 Million).

To make sure that responses were accurate, the researcher sought the help of a Tagalog language expert to translate each indicator in Tagalog for easy understanding of the questions provided.

To ensure the validity of the questionnaire, the purpose of the study and the specific questions were thoroughly reviewed following the construction of the questionnaires. For the background knowledge in making the said questionnaire, the researchers have gone through online journals and articles to come up with questions that would specifically address the concern of the study.

To ensure the reliability of the questionnaire, content analysis was done. The questions were constructed on one-to-one basis with the specific problems. Nonetheless, the contents of the study were analyzed on the basis of the questions frame.

The researchers used the following Mathematical operations. Frequency in tabulating the responses, percentage in tabulating the demographic profile of the respondents and weighted mean which is a type of mean that is calculated by multiplying the weight associated with an event or outcome and then summing up all the products together. It is very much useful when calculating a theoretically-expected outcome in which each factor shows a different probability of occurrence (Weighted Mean, 2019).

\subsection{Some Common Mistakes}

- The word "data" is plural, not singular.

- The subscript for the permeability of vacuum 0 , and other common scientific constants, is zero with subscript formatting, not a lowercase letter "o". 
- In American English, commas, semi-/colons, periods, question and exclamation marks are located within quotation marks only when a complete thought or name is cited, such as a title or full quotation. When quotation marks are used, instead of a bold or italic typeface, to highlight a word or phrase, punctuation should appear outside of the quotation marks. A parenthetical phrase or statement at the end of a sentence is punctuated outside of the closing parenthesis (like this). (A parenthetical sentence is punctuated within the parentheses).

- A graph within a graph is an "inset", not an "insert". The word alternatively is preferred to the word "alternately" (unless you really mean something that alternates).

- Do not use the word "essentially" to mean "approximately" or "effectively".

- In your paper title, if the words "that uses" can accurately replace the word "using", capitalize the "u"; if not, keep using lower-cased.

- Be aware of the different meanings of the homophones "affect" and "effect", "complement" and "compliment", "discreet" and "discrete", "principal" and "principle".

- Do not confuse "imply" and "infer".

- The prefix "non" is not a word; it should be joined to the word it modifies, usually without a hyphen.

- There is no period after the "et" but a period after the "al" in the Latin abbreviation “et al.".

- The abbreviation "i.e." means "that is", and the abbreviation "e.g." means "for example".

\section{Results}

This chapter presents the tabulated results of the data that were gathered in as far as this research type is concerned.

Table 1 shows the demographic profile of the respondents according to age. The tabulation showed that the age with the highest frequency are those with ages 61 years old and above and a percentage of 28.19. This was closely followed by the age bracket 47 - 53 with 57 respondents at 16.13 percent, 9 years of age and below with a frequency of 48 at 13.67 percent. Following just nearby were ages 40 - 46 and 10 - 17, respectively, with frequencies of 39 and 37, and percentages of 11.15 and 10.54. Next were ages 54 - 60 with a frequency 9 with a percentage of 9.24, followed by ages 33 - 39 with a frequency of 20 and at 5.64 and lastly, 18 - 25 years of age with a frequency of 18 and a percentage of 5.13.

Table 2 shows the demographic profile of respondents according to age. It showed that there were more female respondents at 208 and a percentage of 59.26 and for males, there were only 143 respondents at a percentage of 40.74 .

Table 3 shows the demographic profile of the respondents according to socio-economic status. Those who belong to the third class had the most number of respondents with 126 at 35.90, followed by class B with 138 respondents and a percentage of 39.32 and the last would be class 1 with 87 respondents. 
Table 1. Demographic profile of respondents according to age.

\begin{tabular}{ccc}
\hline Age Bracket & Frequency & Percentage \\
\hline 9 years old-below & 48 & 13.67 \\
$10-17$ years old & 37 & 10.54 \\
$18-25$ years old & 12 & 3.42 \\
$26-32$ years old & 6 & 1.71 \\
$33-39$ years old & 20 & 5.69 \\
$40-46$ years old & 39 & 11.11 \\
$47-53$ years old & 57 & 16.24 \\
$54-60$ years old & 32 & 9.12 \\
61 -above & 100 & 28.49 \\
TOTAL: & 351 & $99.99 \%$ \\
\hline
\end{tabular}

Table 2. Demographic profile of respondents according to gender.

\begin{tabular}{ccc}
\hline Gender & Frequency & Percentage \\
\hline Male & 143 & 40.74 \\
Female & 208 & 59.26 \\
TOTAL: & 351 & $100.00 \%$ \\
\hline
\end{tabular}

Table 3. Demographic profile according to socio-economic status.

\begin{tabular}{ccc}
\hline Socio-economic Status & Frequency & Percentage \\
\hline Class A (Upper Class) & 87 & 24.79 \\
Class B (Middle Class) & 138 & 39.32 \\
Class C (Lower Class) & 126 & 36.7 \\
TOTAL: & 60 & $100 \%$ \\
\hline
\end{tabular}

Table 4 is a summary of the overall weighted means (OWM) of the indicators in the different programs of CAS. It showed that Languages Department's Literacy Program ranked first with its OWM of 4.65, it has an overall interpretation of very highly beneficial, it means that the program is highly sustainable, coming closely is Math and Science Department's Environmental Awareness Program which had an 0WM of 4.54, the term means that it is also very highly beneficial and a remark of Highly sustainable for it is in the $2^{\text {nd }}$ rank. Coming out on the third is Physical Education's Wellness Program which had an OWM of 4.33 with means that it is Highly Beneficial there by getting a signal that it is sustainable. Coming next at $4^{\text {th }}$ is the Psychology Department's Behavioral Program with an OWM of 3.79, a verbal interpretation of Highly Beneficial which means the program is sustainable. On the $5^{\text {th }}$ rank is Political Science department's Legal Awareness Program with an OWM of 3.35 which means that it is Beneficial, this means that the program can still be improved. On the last rank is the Social Science Department's History Society which had an OWM of 3.27 and a verbal interpretation of Beneficial which means that the program can still be improved. 
Table 4. Overall summary on the sustainability of CAS community programs in Brgy. Masalipit.

\begin{tabular}{|c|c|c|c|c|c|}
\hline Course & Program & $\begin{array}{l}\text { Overall Weighted } \\
\text { Mean (OWM) }\end{array}$ & $\begin{array}{c}\text { Verbal } \\
\text { Interpretation } \\
\text { (VI) }\end{array}$ & Remarks & Rank \\
\hline Psychology & $\begin{array}{c}\text { Mental Health } \\
\text { Awareness }\end{array}$ & 3.79 & $\begin{array}{l}\text { Highly } \\
\text { Beneficial }\end{array}$ & Sustainable & 4 \\
\hline Languages & $\begin{array}{l}\text { Literacy } \\
\text { Program }\end{array}$ & 4.65 & $\begin{array}{l}\text { Very Highly } \\
\text { Beneficial }\end{array}$ & $\begin{array}{c}\text { Highly } \\
\text { Sustainable }\end{array}$ & 1 \\
\hline Pol. Science & $\begin{array}{c}\text { Legal } \\
\text { Awareness }\end{array}$ & 3.35 & Beneficial & Improvable & 5 \\
\hline $\begin{array}{c}\text { Social } \\
\text { Science/History }\end{array}$ & $\begin{array}{l}\text { History } \\
\text { Society }\end{array}$ & 3.27 & Beneficial & Improvable & 6 \\
\hline $\begin{array}{c}\text { Physical } \\
\text { Education (PE) }\end{array}$ & $\begin{array}{l}\text { Wellness } \\
\text { Program }\end{array}$ & 4.33 & $\begin{array}{l}\text { Highly } \\
\text { Beneficial }\end{array}$ & Sustainable & 3 \\
\hline $\begin{array}{c}\text { Science \& } \\
\text { Mathematics }\end{array}$ & $\begin{array}{c}\text { Environmental } \\
\text { Awareness }\end{array}$ & 4.54 & $\begin{array}{l}\text { Very Highly } \\
\text { Beneficial }\end{array}$ & $\begin{array}{c}\text { Highly } \\
\text { Sustainable }\end{array}$ & 2 \\
\hline & & GM-3.98 & & & \\
\hline
\end{tabular}

\section{Discussion}

The following important data were gathered in adherence to the research conducted. As regards the demographic profile of the respondents shown in Table 1 (Demographic Profile of Respondents According to Age), in terms of age, it has been found out that majority of the respondents in Brgy. Masalipit had ages 61 years old and above. It can be gleaned that in a place with a total population of 2886, most are really elders since it is a small town where the most prominent livelihood of the local residents are either farming or tending to some animals. Next are those whose ages range from $47-53$ (57 at 16.13\%), 9 years-below (48 at $13.67 \%)$ and $40-46$ (39 at 11.15\%), respectively, including ages ranging from $10-17$ (37 at 10.54\%), $54-60$ (32 at 9.24), $33-29$ (20 at 5.64\%) and $18-25$ (18 at $5.13 \%)$. This only shows how participative the residents were in the community which served as the setting of the study, and how timely the research that it can be beneficial primarily for all age ranges.

In terms of the respondents' gender as shown in Table 2 (Demographic Profile of Respondents According to Gender), more females participated in the research than males for there were only 143 males (at 40.75\%) while the females were all in all 208 (at 59.26\%). This is because every time the research would go take place, they see to it that they come along with other CAS departments who are also scheduled to have an activity in the community. The usual time is around $10 \mathrm{am}-12 \mathrm{nn}$, a time when mostly mothers can be found available, either with their children at the day care center or within their homes cooking for something that their family could eat for lunch, while the males are mostly not around because they are still in the fields tending those crops that they have planted. 
As regards the respondents' socio-economic status shown in Table 3 (Demographic Profile of Respondents According to Socio-Economic Status), the researchers, as they visit the Barangay and some of the offices of concern in the community such as office of the social welfare or the Barangay census, they would easily explain that in their community, there are only three social classes, and these are similar to those classes described by the researchers. Class B has most number of respondents with a frequency of 138 at $39.32 \%$, followed by Class $\mathrm{C}$ which has 126 respondents at $35.90 \%$ and lastly, those respondents who belong to Class A have the lowest frequency with only 87 at $24.77 \%$. According to some local individuals, although most of them are farmers, not most of them live in poverty because most are owners of vast lands whom they toil or convert into other forms of asset.

How beneficial are the CAS Community Extension Programs in Brgy. Masalipit in raising awareness in areas such as the following:

1) Literacy;

2) Wellness of the Body;

3) Wellness of the Mind;

4) Environmental;

5) Historical; and

6) Legal aspect in a person's personality?

Table 4 (Overall Sustainability of CAS Community Programs in Brgy. Masalipit) shows a summary of pertinent details that were gathered in relation to the research that was conducted. It showed that the programs of Languages (Literacy Program) and Science Mathematics department (Environmental Awareness) were in the highest rank (OWM 4.65-Languages, 4.54-Science \& Math) having a remark of Very Highly Beneficial which means that both programs are highly sustainable and can still continue on because of the benefits it produces. Physical Education Department's Wellness Program and Psychology Department's Behavioral Awareness were in the third and fourth rank (OWM 4.33-PE and 3.79-Psychology) described as Highly Beneficial which means that both programs are sustainable although some changes may be made or modified for the betterment of the project. Political Science's Legal Awareness and Social Science $\&$ History Department's History Society ranked $5^{\text {th }}$ and $6^{\text {th }}$, respectively with an OWM 3.35 (Pol. Scie) and an OWM of 3.27 (Social Science/History) which is described as Beneficial. This means that the said program can still be improved or enhanced so that it can serve its purpose of helping the people in the community.

\section{Conclusion}

The above foregoing findings (Table 4) show the competency of some programs under the College of Arts and Sciences in the community setup. The Literacy Program of the Languages department and the Environmental Awareness Program of Science and Mathematics department were found to have been very highly beneficial which means that this program is highly sustainable and can 
carry through within the next couple of years because of its proven effects and benefits in its stakeholders. However, there were some programs which were not as effective nor as sustainable as the first two. This means that the program needs repackaging or enhancement for further improvement. In a lecture delivered by Osmond regarding the sustainability of certain community projects and programs (2012), He stressed out that it is important to identify the objective of every community program, it should always be at the forefront of every endeavor so that the efforts exerted by every person involved is not wasted.

As regards the research's impact on the community, it has been identified highly useful and significant with special emphasis on the Literacy and Environmental Awareness Programs. The students need to open their eyes on the importance of these community programs as it widens their horizon and experiences. As the expert educators say, learning is not just confined to the four corners of the classroom. The students need to personally witness learning situations and instances like this so that it would leave a mark that could influence their lives to become more meaningful.

In a more careful analysis of the situation, it can be noted that at the start of the literacy program, students were shy, timid and afraid to take part in the discussions in the class. The reading and story-telling sessions were boring because of the lack of participation of the learners. As time went by, and because of the diligence and perseverance of our program implementers, the students slowly became active and participative in class. Discussions now have become lively and enjoyable especially when the students are seen enjoying and having a good time with our student facilitators. The most rewarding of which is when these students get promoted to the next level of learning. This is a clear proof that the program was successful in combating illiteracy at the initial phase. The fight still continues and we do not intend to stop until we make sure that these students have fully mastered the necessary skills of becoming educated and literate individuals.

\section{Recommendations}

Therefore, the findings in the study prompted the researchers to propose important recommendations to enhance and develop some of the programs under CAS:

1) Continued assessment of the effectiveness of each program in as far as community setup is concerned.

2) Advanced planning and creation of new programs relative to the previous ones and the needs of the community that would augment or continue the program that is about to come to pass or may have ended.

The local government of Barangay Masalipit needs to conduct capacity development, it is a process by which individuals and organizations try to improve and retain the skills, knowledge, tools, equipment, programs implemented and even other resources for a more effective and meaningful implementation. This 
activity will pave the way to advanced planning or design of other programs that can bridge the gap or shortcomings of the existing programs. This endeavor will also determine the need for creating follow-up programs to those programs which have been successful and competent enough in terms of producing desirable results. As regards those programs which have not been that quite effective, capacity building development can also help in identifying which areas of these less-effective programs need to be revisited so that it can be strengthened and improved.

3) Community mapping to identify the perceived needs of the community in all sorts and aspects.

Community mapping is the process and product of the community getting together to map its own assets, values, beliefs or any other self-selected variable. It is about mapping by the community using relatively informal processes. It is opposite to mapping by authority for authority using formal rules. In this specific aspect, the researchers think that the concept of community mapping can best be done to know more not just about the available resources of the community, but moreover, to know also what other services the community needs, the equipment and facilities they lack and also the assessment of the community programs that need strengthening, refurbishing or further enhancement. Based on the gathered data, the researchers have already identified what programs were effective and that needs further enhancement so that it may help the entire people in the community. The programs which were not successful and that need further refurbishing or enhancement were at the same time identified so that the authorities can study and hopefully produce more noteworthy projects that could really bring about significant change in the community.

Due to limited resources and distance, including the preoccupied schedules in holding classes, the researchers were not able to constantly visit the community for purposes of assessment and monitoring. Although the researchers made sure that during the research conduct, they visited the community as they take turns from doing so since they have different class schedules. Another future shortcoming of this research is the possible abrupt discontinuation of the programs that were designed and implemented after the upcoming local and national elections (midyear of 2022). Since these programs were approved and implemented upon the approval of the Barangay officials who have greatly cooperated with the school, there might be a possibility that these programs may be junked off especially if the next roster of Barangay officials were not in good terms with the previous ones. It has been a practice in most provinces of the country that if new officials would rise to power, they try to replace everything and discontinue everything, including the existing programs.

\section{Conflicts of Interest}

The authors declare no conflicts of interest regarding the publication of this paper. 


\section{References}

D’ Anna, C. (2020). Five Ways to Start a Hydrophonic Garden. USA. https://www.thespruce.com/

Dudovskiy, J. (2020). Purposive Sampling. https://research-methodology.net/

Weighted Mean (2019). https://corporatefinanceinstitute.com/ 